\title{
Swimming performance of subarctic Calanus spp. facing downward currents
}

\author{
N. Weidberg ${ }^{1,4, *}$, C. DiBacco ${ }^{2}$, C. Pezzola ${ }^{1,5}$, E. Rebiffe ${ }^{1,3}$, S. L. Basedow ${ }^{1}$ \\ ${ }^{1}$ Department of Arctic and Marine Biology, UiT The Arctic University of Norway, 9019 Tromsø, Norway \\ ${ }^{2}$ Fisheries and Oceans Canada, Bedford Institute of Oceanography, Dartmouth, B2Y 4A2 Nova Scotia, Canada \\ ${ }^{3}$ National School for Environmental and Water Engineering, University of Strasbourg, 67070 Strasbourg, France \\ ${ }^{4}$ Present address: Department of Biological Sciences, University of South Carolina, 29208 Columbia, South Carolina, USA \\ ${ }^{5}$ Present address: Faculty of Sciences and Engineering, University of Groningen, 9701 Groningen, The Netherlands
}

\begin{abstract}
Calanoid copepods dominate mesozooplankton communities in temperate and Nordic seas. The ability of copepods to remain and feed in productive surface waters depends on their ability to overcome downward flows. In this study, we assessed the swimming performance of subarctic Calanus spp. and tested how the copepods can retain their vertical position in a representative range of downward currents (between 0 and $5.4 \mathrm{~cm} \mathrm{~s}^{-1}$ ) simulated in a downwelling flume. Mean vertical and horizontal copepod swimming velocities and accelerations, movement periodicity and trajectory complexity were obtained by tracking individual trajectories in the field of view of 2 cameras. Copepod swimming velocity increased with increasing downward flow and matched downward flows up to $2 \mathrm{~cm} \mathrm{~s}^{-1}$. Beyond $2 \mathrm{~cm} \mathrm{~s}^{-1}$, animals were still able to significantly reduce their sinking rates, but their motions changed. Trajectories became simpler, swimming velocities changed on shorter time scales and instantaneous acceleration increased. These results are consistent with predictions of balancing depth retention against encounter rates with food and predators. Frequency distributions of vertical swimming speeds were mostly unimodal, with entire experimental populations responding in the same way. Coordination of movements and the ability to resist moderate downwelling flows can result in the accumulation of copepods in large surface swarms as observed in the field.
\end{abstract}

KEY WORDS: Calanoid copepods $\cdot$ Swimming behaviour $\cdot$ Depth retention $\cdot$ Downwelling currents

\section{INTRODUCTION}

Mesozooplankton constitute about 9.5\% of total animal biomass on Earth; thus, they are a key component of marine pelagic ecosystems and play a central role in biogeochemical cycles on a global scale (Moriarty \& O'Brien 2013, Le Quéré et al. 2016). These animals typically swim at speeds of several $\mathrm{mm} \mathrm{s}^{-1}$ and are subjected to rather strong horizontal flows of many $\mathrm{cm} \mathrm{s}^{-1}$; thus, they have been traditionally perceived as passive tracers of ocean currents (Mann 1988, Archambault et al. 1998). However, vertical flows in the oceans are usually weaker and can be overcome by

*Corresponding author: j_weidberg@hotmail.com zooplankton that swim at comparable speeds. In fact, many different behaviours across the water column have been reported, including diel vertical migrations (Barham 1963, Enright 1977), tidal vertical migrations across estuaries (Queiroga \& Blanton 2004), depth retention against Ekman transport (Genin et al. 2005, Shanks \& Brink 2005, Shanks \& Shearman 2009) and surface accumulations against convergent downward flows at fronts on different spatial scales (Pineda 1999, Shanks et al. 2000, Weidberg et al. 2014). These active responses provide a wide range of selective advantages, including predator avoidance, onshore transport for coastal zooplankton and meroplankton

() N. Weidberg, C. Pezzola, E. Rebiffe, S. L. Basedow, and Fisheries and Oceans Canada 2021. Open Access under Creative Commons by Attribution Licence. Use, distribution and reproduction are unrestricted. Authors and original publication must be credited. Publisher: Inter-Research - www.int-res.com 
and accumulation at hydrographic features rich in food.

Calanoid copepods dominate the mesozooplankton community, usually comprising more than $50 \%$ of total mesozooplankton biomass in pelagic systems (Carstensen et al. 2012). In the North Atlantic Ocean and subarctic seas, Calanus finmarchicus is the dominant calanoid copepod and is known to exhibit extensive seasonal vertical migrations. From their overwintering depths at 800-1000 m, they migrate to the surface layer at the onset of the spring phytoplankton bloom. Then, once the next generation has reached copepodite stages IV-V in late summer, they descend to overwintering depths (Hirche 1996, Halvorsen et al. 2003). Such large vertical migrations are regulated by this copepod's lipid components, which change their relative density to the surrounding seawater with concomitant changes in pressure and temperature as the animals ascend or descend (Visser \& Jónasdóttir 1999, Weidberg \& Basedow 2019). Upward spring migrations may be largely passive, as the ascent is probably triggered by the consumption of the densest lipid components by the end of winter so that the copepods become lighter than the surrounding waters. This process speeds up as the copepods ascend and reach warmer and shallower water layers (Pond \& Tarling 2011). However, active downward swimming may be required at the beginning of the late-summer descent, as the overwintering copepodite stages IV and V are positively buoyant when the descent starts (Pond \& Tarling 2011). Before reaching such a lipid-rich buoyant stage, the copepods have to remain in the surface layer to graze on phytoplankton throughout spring and summer. At this point they are still not positively buoyant and rely on upward swimming behaviours to remain in the productive layer. Thus, the ability of these animals to swim upward may be a key feature in their life cycle and, given their high abundances, also in the functioning of the entire pelagic trophic web.

Upward swimming not only allows northern calanoid copepods to stay in the surface layer, but may also contribute to the development of large-scale swarms. Reddish surface accumulations of $C$. finmarchicus were observed at the beginning of the $20^{\text {th }}$ century off northern Norway (Sars 1903). Recently, a large surface swarm spanning more than $1000 \mathrm{~km}^{2}$ was observed with the VIIRS satellite off the Lofoten Archipielago, making it the first mesozooplankton shoal to be observed from space (Basedow et al. 2019). These surface swarms of copepods can feed on the phytoplankton blooms, but also offer a clear target for visual predators like storm petrels, small pelagics like herring Clupea harengus, and macrozooplankton (e.g. chaetognaths) (Croxall et al. 1988, Bonnet et al. 2010, Bachiller et al. 2016). In fact, the timing and amplitude of vertical migrations in copepods is finely tuned by a balance between potential energetic gains and the risks of predation at the surface layer (Fiksen \& Carlotti 1998). At greater depths, both visual predators and food availability are largely reduced (Enright 1977), and increased hydrostatic pressure may negatively affect grazing in calanoid copepods (Zarubin et al. 2016). In the highly productive Nordic Seas in spring, the suppression of large-scale diel vertical migration in favour of surface grazing revealed a trade-off between predation risks and feeding opportunities that skewed towards the latter. Even within the surface layer, copepods still modified swimming trajectories to minimise predator encounter rates while maintaining a minimum feeding performance (Visser \& Kiørboe 2006). This predation-feeding trade-off leads to the optimisation of the minimum distance travelled by organisms without a significant change in direction (i.e. correlation length scale), which has to be longer than the reaction distances of their prey but shorter than those of predators (Taylor 1921, van Duren \& Videler 1996, Visser \& Kiørboe 2006). The correlation length scale is the product of swimming velocity and the time required for the animal to cover such distance. However, these taxa-specific optimal times and distances have been studied under static laboratory conditions for plankton and in the absence of any vertical flow. In the ocean, copepods are forced to swim faster to keep their vertical position when facing downwelling currents, which may result in adjustments of these temporal and spatial scales. How swimming trajectories and overall animal behaviour are affected by such changes is largely unknown.

To evaluate the ability of calanoid copepods to swim independently of water flow, different experiments and field observations have been carried out in the past. C. marshallae have been observed to swim at speeds up to $5.6 \mathrm{~cm} \mathrm{~s}^{-1}$ when searching for females during mating (Tsuda \& Miller 1998), while normal cruising speeds in C. sinicus are on the order of $1 \mathrm{~cm}$ $\mathrm{s}^{-1}$ (Chen \& Hwang 2018). Instantaneous escape responses, which occur when the animal reacts to deformations of the flow field potentially associated with a predator in their surroundings, can attain speeds from 10-100 $\mathrm{cm} \mathrm{s}^{-1}$ for C. finmarchicus (Haury et al. 1980, Lenz et al. 2004, Kiørboe et al. 2010, Fields et al. 2012). Hardy \& Bainbridge (1954) estimated a maximum velocity of $1.8 \mathrm{~cm} \mathrm{~s}^{-1}$ for $C$. finmarchicus undergoing large-amplitude upward vertical migrations. 
Accordingly, similar vertical speeds of calanoid copepods were observed with acoustic Doppler current profilers off the Scottish west coast and off Svalbard, Norway (Tarling et al. 2002, Cottier et al. 2006). These vertical speeds, although relatively high, can be overcome by strong downward flows of several $\mathrm{cm} \mathrm{s}^{-1}$ at the surface layer driven by winds and internal waves off the Norwegian coast (Sætre 1999, Dokken et al. 2001).

In this study, we employed a downwelling flume initially developed by DiBacco et al. (2011) to experimentally assess vertical swimming speeds and behaviours of Calanus spp. copepods in response to controlled and variable downward flows. This flume was initially developed and used to characterise vertical swimming speed and behavioural responses of barnacle cyprids Semibalanus balanoides by simulating vertical flows typical of coastal convergent fronts where accumulations of these larvae were observed (Pineda 1999, Weidberg et al. 2014). Similarly, we recorded and characterised active swimming responses of subarctic Calanus spp. copepods to realistic flows occurring within the surface layer off the Norwegian coast to infer copepod behaviour in their spring habitat. We hypothesised that these animals should be able to counter downwelling flows between several $\mathrm{mm} \mathrm{s}^{-1}$ to a few $\mathrm{cm} \mathrm{s}^{-1}$, while keeping a characteristic range of correlation length scales at the expense of abrupt changes in their swimming trajectories. The ability of the animals to provide a uniform behavioural response to different flow conditions among individuals and to coordinate their movements along time was also examined.

\section{MATERIALS AND METHODS}

\subsection{Experimental cylinder}

A downwelling flume, based on the one developed by DiBacco et al. (2011), was constructed to simulate downwelling currents in a closed and controlled environment. The flume consisted of a $0.9 \mathrm{~m}$ inner observational chamber contained in a recirculating water jacket that provided temperature control. This flume was the same as used by DiBacco et al. (2011), but we connected the observational chamber to a different pump (M\&E Marathon pump) by a PVC pipe that recirculated water into the chamber through the top and exited the bottom. This upper portion of the chamber consisted of a water diffusing region filled with marbles that created a uniform plug flow in the lower half of the chamber where videos were re- corded (DiBacco et al. 2011). The lower part of the inner chamber was perforated by holes of $1 \mathrm{~mm}$ of diameter to allow for the circulation of particles and copepods, and by injection ports to introduce particles and copepods at the right height inside the chamber, where uniform flow was attained (30$40 \mathrm{~cm}$ below the water diffusing region; DiBacco et al. 2011). An in-line pressure gauge, thermometer, and pressure release valve were installed on the upper PVC pipe to monitor water flow conditions. The pump was wired to a Hitachi NE-S1 digital inverter to control and change the pump rate and, in turn, the downwelling water velocities inside the chamber.

\subsection{Experimental setup}

Seawater was obtained from the fjord Balsfjorden close to UiT The Arctic University of Norway through a circulation system with a $150 \mu \mathrm{m}$ filter. Before filling the experimental cylinder and in order to minimize accumulation of bubbles due to degassing, seawater was allowed to warm to approximately $15^{\circ} \mathrm{C}$ for at least $12 \mathrm{~h}$ in a $2.3 \mathrm{~m}^{3}$ water tank. Thus, pressure and temperature were equilibrated to those in the experimental room, which allowed degassing (DiBacco et al. 2011). This water was pumped into the experimental chamber through a 1 way valve. However, this procedure led to a significant water warming above $11^{\circ} \mathrm{C}$ even with flowing seawater in the outer chamber. Thus, for the experiments with copepods, temperatures were cooled by adding $20 \mathrm{~m}$ of silicon pipe inside a $40 \mathrm{l}$ electric cooler filled with ice. In this way, the water was circulated through the cooler when filling the cylinder, thus keeping water temperatures between 9 and $11^{\circ} \mathrm{C}$, close to the range experienced by the animals in the upper water column (see Section 2.3). Fluorescent lights were located approximately $1 \mathrm{~m}$ above the top of the observation chamber. Photosynthetically active radiation (PAR) was measured with a LI250A light meter. PAR ranges in the room were around $6 \mu \mathrm{mol} \mathrm{m}{ }^{-2} \mathrm{~s}^{-1}$, and thus within the lower range of light levels observed in the upper $10 \mathrm{~m}$ of the water column during spring $2018\left(5-915 \mu \mathrm{mol} \mathrm{m}^{-2} \mathrm{~s}^{-1}\right.$; authors' unpubl. data)

Videos were recorded by 2 E-M10 Mark II Olympus cameras positioned orthogonally and mounted on tripods at a height of $35 \mathrm{~cm}$ from the top of the inner chamber that enabled recording within the uniform flow region (DiBacco et al. 2011). Cameras were placed perpendicular to each other in front of 2 of the 4 sides of the chamber. The other 2 sides were 


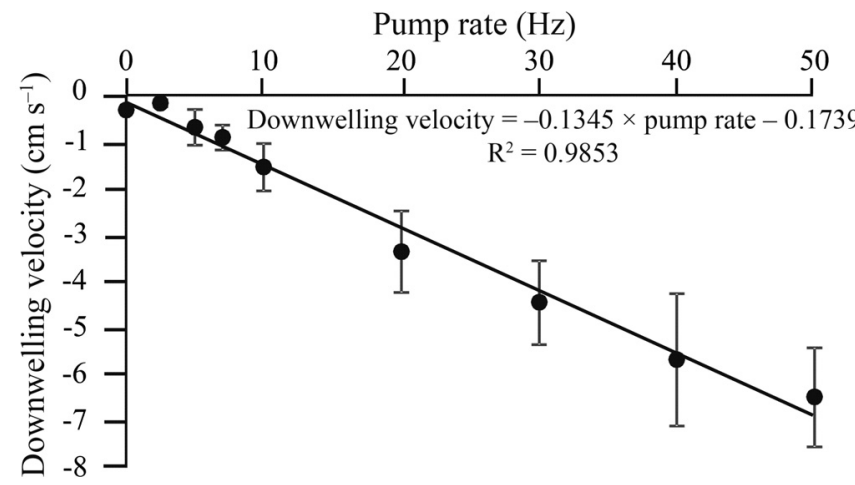

Fig. 1. Calibration of pump rate against water velocity using particles. Mean $( \pm \mathrm{SD})$ measured velocities are shown for each pump rate tested. The number of observations ranged from 16-52 particles per pump rate. The calibration equation with its variance explained is also shown

covered by black cardboard to increase the colour contrast between copepods/particles and the background. High-resolution videos $(1080 \times 1920$ pixels $)$ were recorded at a rate of $50 \mathrm{~Hz}$. The fields of view were relatively narrow $\left(5.6 \times 9.8 \mathrm{~cm}\right.$ for Camera $\mathrm{A}_{\text {; }}$ $6.4 \times 11.2 \mathrm{~cm}$ for Camera B) to avoid potential visual artefacts caused by the curved walls of the chamber (DiBacco et al. 2011). In addition, the depth of field was narrow (ca. $2 \mathrm{~cm}$ ) to optimize focus of small animals and particles recorded at short distances (ca. $35-40 \mathrm{~cm}$ ). Thus, the area where the 2 fields of view overlapped was reduced, preventing a simultaneous tracking of the same individual and the reconstruction of 3D trajectories

To determine mean downwelling velocities of water at different pump rates (i.e. different experimental treatments) that copepods were subjected to, the trajectories of near-neutrally buoyant particles were video-recorded and velocities determined via image analysis (see Section 2.5). The particles used here were fluorescent green polyethylene microspheres with a diameter that ranged from $710-850 \mu \mathrm{m}$ and a density of $1.025 \mathrm{~g} \mathrm{~cm}^{-3}$ (www.cospheric.com/UVPMSBG_fluo rescent_green_spheres_density1025htm). Their density approximately equalled that of seawater from the fjord (ca. $1.02543 \mathrm{~g} \mathrm{~cm}^{-3}$ at surface). The particle's color contrasted with the dark background and in turn facilitated trajectory tracking. As the particles were hydrophobic, they were coated with a $0.2 \%$ solution of the surfactant Tween 80 before immersion. Particles were introduced through an injection port with a $20 \mathrm{ml}$ syringe. For each calibration trial, $2 \mathrm{~g}$ of particles (ca. 8000 particles) were used and videos of $2.5 \mathrm{~min}$ were recorded and analysed at pump rates of $0,2.5,5,7,10,20,30,40$ and $50 \mathrm{~Hz}$.
Between 2 and 6 videos were recorded for each pump rate tested. Particles were recovered by a $100 \mu \mathrm{m}$ sieve when emptying the cylinder.

Vertical water velocities measured by the motions of inert passive particles were highly correlated with pump rates (Fig. 1). Downwelling velocities increased at a rate of $0.1345 \mathrm{~cm} \mathrm{~s}^{-1} \mathrm{~Hz}^{-1}$ to a maximum of $-6.72 \mathrm{~cm} \mathrm{~s}^{-1}$ at $50 \mathrm{~Hz}$. The calibration line had a significant intercept of $-0.1739 \mathrm{~cm} \mathrm{~s}^{-1}$ at $0 \mathrm{~Hz}$, meaning that particles were slightly and negatively buoyant on average. Thus, this intercept was subtracted from theoretical vertical velocities obtained from the calibration equation in order to estimate true vertical water velocities.

\subsection{Copepod collection}

Plankton tows (WP2, $0.19 \mathrm{~m}^{2}$ mouth opening, $180 \mu \mathrm{m}$ mesh) were carried out aboard the $12 \mathrm{~m} \mathrm{R} / \mathrm{V}$ 'Hyas' at the mouth of Ramfjord $\left(69.5244^{\circ} \mathrm{N}, 19.0207^{\circ} \mathrm{E}\right)$ on 17 June 2019. In total, 11 vertical plankton tows were conducted from a depth of $50 \mathrm{~m}$ to the surface at a speed of $0.5 \mathrm{~m} \mathrm{~s}^{-1}$. Net contents were concentrated into two $0.2 \mathrm{~m}^{3}$ buckets filled with surface water. The buckets were closed and covered with black plastic bags to help preserve temperature during transport back to the laboratory (60 min). Depth at the collection station was $132 \mathrm{~m}$; CTD casts conducted a few days earlier at the same site indicated temperatures between 8 and $11^{\circ} \mathrm{C}$ within the upper $50 \mathrm{~m}$. The buckets were quickly transferred to a cold room at the university and ctenophores and siphonophores removed to avoid predation on copepods. To recreate environmental conditions, temperature was kept constant $\left(7-8^{\circ} \mathrm{C}\right)$ and light was constantly on. Buckets were provided with continuous aeration, and the whole water volume was replaced with ambient, filtered seawater every $24 \mathrm{~h}$. Each bucket of copepods were fed daily with a cultured diatom, Porosira glacialis, at a density of 395 cells ml$^{-1}$ in $450 \mathrm{ml}$ of seawater.

\subsection{Copepod experiments}

For each experimental replicate, approximately 200-500 Calanus spp. stage IV/V copepodites were extracted using plastic pipets and $100 \mu \mathrm{m}$ sieves. $C$. finmarchicus tends to dominate in fjords around Tromsø, but genetic markers have identified a few $C$. glacialis in northern Norwegian fjords as well (Choquet et al. 2017). Both species can overlap in size and cannot be identified morphologically. Based on ear- 
lier analyses, we assume our experimental copepods were C. finmarchicus, but the presence of C. glacialis cannot be completely ruled out. Individuals were concentrated in 50-60 ml of filtered seawater and introduced into the chamber through an injection port with a syringe. They were allowed to acclimate for at least 5 min before the pump was switched on at the desired frequency, and videos were recorded for 3-10 min. Each group of 200-500 individuals was employed in only one experimental replicate (i.e. exposed one time to only one experimental downwelling velocity treatment). A total of 16 experiments were carried out 1-3 d after animal collection (from 18-20 June 2019) at pump rates of 0, 2.5, 5, 7, 10, 20, 30 and $40 \mathrm{~Hz}$ (Table S1 in the Supplement at www. int-res.com/articles/suppl/m665p047_supp.xlsx).

\subsection{Video processing}

Tracker software (v.5.0.7) was employed to analyze particle and copepodite trajectories. Pixel positions ( $x-y$ coordinates) of particles/animals remaining within the cameras field of views were recorded frame-by-frame (every $0.02 \mathrm{~s}$ ). As the cameras were deployed with no inclination relative to the floor, $x$ and $y$ coordinates provided by the software were considered as positions along the horizontal and zenith-nadir axes, respectively. The width of the injection port $(0.8 \mathrm{~cm})$ was used to calibrate pixel coordinates to $\mathrm{cm}$. Eventually, time series of spatial positions were obtained for every particle/copepod on every video. Depending on the camera, downwelling velocity and experiment, the length of these time series ranged from $0.44-12.26 \mathrm{~s}$ for copepods and from $0.88-5.92 \mathrm{~s}$ for particles. The number of copepod trajectories recorded and tracked on each experiment ranged from 13-146, with fewer observations with Camera A especially at higher downwelling currents (Table S1).

\subsection{Copepod swimming speed and behaviour}

The horizontal and vertical distances covered by the animals during time intervals (frame rate: $50 \mathrm{~Hz}$ ) were used to calculate instantaneous vertical and horizontal velocities, which were averaged over the entire recorded trajectory of each individual copepod to get representative means. In the vertical axis, swimming velocities relative to ambient flowing waters were calculated by subtracting water velocities based on calibrations with the passive particles (see Section 2.2). Changes in velocity between time frames were used to calculate mean accelerations along both axes. To simplify calculations and account for variability in mean speed, absolute acceleration values were considered instead of positive and negative accelerations. An index of trajectory complexity was calculated for each individual as the ratio of total distance covered by the animal and the straight line distance between initial and final trajectory positions. Thus, more simple trajectories would present index values close to 1 as the total distance would be similar to the shortest possible, while much higher values could be attained if trajectories are convoluted. This index is the inverse of the net-to-gross displacement ratio (NGDR; Buskey 1984)

All descriptors of copepod behaviour (i.e. horizontal and vertical swimming velocities, horizontal and vertical absolute accelerations, dominant periods in horizontal and vertical swimming velocities and trajectory complexity) were used as dependent variables in ANOVAs with statistical significance determined by $\alpha=0.05$. For simplicity, we assumed that each individual trajectory corresponded to a different individual, but it is possible (although unlikely) that the same individual re-appeared in the field of view after some time. Camera, with levels A and B, and water velocity, with 8 levels (Table S1), were selected as factors in orthogonal factorial designs that incorporated the interaction of camera $\times$ water velocity. Data from different experiments at the same water velocities were pooled for this analysis to simplify the statistical design and increase its power. As acceleration and trajectory complexity index values showed heterogeneous variances among factor levels and skewed, less normal distributions, these were log transformed prior to analysis resulting in $\mathrm{p}$-values $>0.4$ after transformation (Levene's test). Significant factors were only considered if the interaction of camera $\times$ downwelling velocity was not significant. In general, the main effects of factors cannot be interpreted if the interaction terms involving those factors become significant (Field 2013). These analyses were performed in the software Statistica V8 (StatSoft).

We considered the characteristic time scale at which copepod velocity fluctuates to be a good proxy of the correlation time scale. To account for changes in this time scale at different downwelling velocities, spectral Fourier analyses were performed on the time series of instantaneous horizontal and vertical velocities along the entire trajectory for each copepod. These analyses allow for the calculation of spectral densities as proxies of the variability in velocity explained by cycles of different periods (R package 
TSA; Chan \& Ripley 2018, R Core Team 2020). Thus, copepod instantaneous velocities fluctuate on time scales with the dominant period obtained from the spectral Fourier analyses (Bianco et al. 2013). Time series shorter than the within-experiment median time duration were eliminated before submitting trajectories to the spectral Fourier analyses. In addition, computed spectral densities were not considered for periods longer than $1 / 3$ of the total length of the time series, as longer periods will not be independent of shorter ones and the statistical power to calculate their spectral densities is reduced (Scargle 1982, Frescura et al. 2008).

Behavioural responses to changes in water flow can operate across the whole population or can differ among groups of animals within the population, which would be reflected in multiple modes. To detect modes in the swimming velocities of the entire population of copepods, multimodality tests were performed for vertical swimming velocities. These tests were developed with probability densities obtained from the frequency distributions of mean vertical swimming velocities of each copepod observed at each experiment. They are based on the premise that modes are located where an excess in the probability density is found (excess mass tests; Muller \& Sawitzki 1991). Statistical significance was obtained by randomly resampling (500 times) the probability density function. Tests were carried out with unimodal distributions $(M=1)$ as the null hypothesis, thus considering $M>1$ as the alternative hypothesis. If this null hypothesis was rejected, then bimodality $(M=2)$ was considered as the new null hypothesis against the alternative hypothesis of $M>2$. For $M>$ 1 , the least frequent values in between modes, called antimodes, were calculated. As a proxy of data dispersal within the probability density functions, bandwidths were computed as free smoothing parameters proportional to the standard deviation (Silverman 1986). Critical bandwidths were calculated as the smallest bandwidths such that the probability distribution contains at most the hypothesised number of modes (Silverman 1981). Tests were computed in $R$ (package 'multimode'; Ameijeiras-Alonso et al. 2019). The multimodality tests show if most copepods in the population swam at the same speed (one mode of vertical velocities, unimodal) or if the population was divided into 2 groups that swam at different speeds (bimodal).

Besides the occurrence of potentially different behaviours within the population, shifts in swimming performance can also occur for the whole population through time as animals start to respond to new flow conditions and synchronise their movements. To account for this source of variability, mean vertical swimming velocities of each copepod were represented along the time duration of the video (ca. $7 \mathrm{~min}$ ) to search for potential synchronised movements in the copepod population. Each point in these plots represents the mean velocity of a given copepod averaged over its whole trajectory. Then, segmented linear regressions were applied to all of these plots. For each one, piece-wise linear relationships with 1,2 and 3 breakpoints were estimated. The statistical significance of these breakpoints was tested with the Davies' test, which evaluates the occurrence of non-zero differences in the slopes of adjacent segments (Davies 2002). The hypothesis was evaluated in 50 equally spaced randomly selected points, and each test was repeated 50 times for each plot and number of breakpoints (1-3) in order to get a robust p-value. Tests were computed in R (package 'segmented'; Muggeo 2019).

To detect a potential behavioural trade-off, dominant periods and trajectory complexity indexes were regressed against vertical swimming velocities for each pump rate/downwelling velocity.

\section{RESULTS}

\subsection{Copepod swimming speed}

A total of 29 tests were carried out from 18-20 June 2019 (Table S1). Copepod swimming velocities increased with the downwelling velocity of water (Fig. 2). In the range between $0-1 \mathrm{~cm} \mathrm{~s}^{-1}$, mean copepod vertical velocities were faster than downwelling currents. Above that range, mean swimming velocities were much lower than downwelling velocities, although they kept increasing with increasing down-

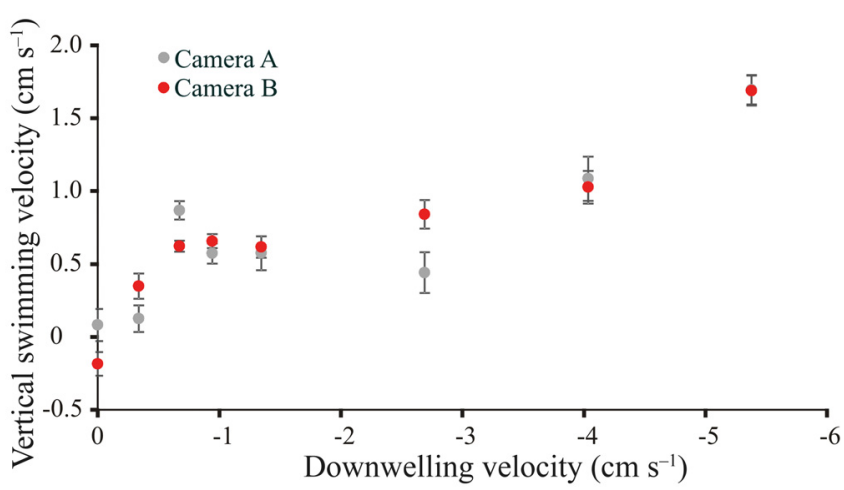

Fig. 2. Vertical swimming velocities at different downwelling velocities. Least square means $( \pm \mathrm{SE})$ from the ANOVA are shown. Only significant factors from this analysis are represented, in this case, camera $\times$ water velocity 
welling to maximum values of around $1.8 \mathrm{~cm} \mathrm{~s}^{-1}$ at downwelling water velocities of $-5.38 \mathrm{~cm} \mathrm{~s}^{-1}$. Significant differences were found between the 2 cameras at some water vertical velocities $(-0.34,-0.67$ and $-2.69 \mathrm{~cm} \mathrm{~s}^{-1}$ ), resulting in a significant interaction of camera $\times$ water vertical velocity (Table 1 ). Horizontal velocities did not vary among velocity treatments or cameras (Table 1).

The copepods' acceleration also increased with downwelling water velocities, peaking at downwelling water velocities of $-4.04 \mathrm{~cm} \mathrm{~s}^{-1}$, while a significant drop was observed at $-5.38 \mathrm{~cm} \mathrm{~s}^{-1}$, especially for vertical accelerations (Fig. 3). Accelerations ranged between 0.38 and $513 \mathrm{~cm} \mathrm{~s}^{-2}$ and between 0.007 and $304 \mathrm{~cm} \mathrm{~s}^{-2}$ for the vertical and horizontal

Table 1. ANOVA results for the different descriptors of copepod swimming behaviour. Significant terms of the models are shown in bold. Mean squares (MS) are presented. Between-groups and within-groups degrees of freedom (df) are reported

\begin{tabular}{|c|c|c|c|c|}
\hline Variables and factors & df & MS & $F$ & $\mathrm{p}$ \\
\hline \multicolumn{5}{|l|}{ Vertical swimming velocity } \\
\hline Intercept & 1,1556 & 449.424 & 810.812 & $<0.0001$ \\
\hline Camera & 1,1556 & 0.106 & 0.191 & 0.661 \\
\hline Downwelling velocity & 7,1556 & 30.447 & 54.929 & $<0.0001$ \\
\hline Camera $\times$ downwelling velocity & 7,1556 & 1.920 & 3.464 & 0.001 \\
\hline \multicolumn{5}{|l|}{ Horizontal swimming velocity } \\
\hline Intercept & 1,1556 & 0.857 & 6.669 & 0.009 \\
\hline Camera & 1,1556 & 0.001 & 0.009 & 0.922 \\
\hline Downwelling velocity & 7,1556 & 0.217 & 1.689 & 0.107 \\
\hline Camera $\times$ downwelling velocity & 7,1556 & 0.072 & 0.566 & 0.783 \\
\hline \multicolumn{5}{|l|}{ Vertical absolute acceleration, log } \\
\hline Intercept & 1,1565 & 1917.587 & 31274.390 & $<0.0001$ \\
\hline Camera & 1,1565 & 0.140 & 2.280 & 0.131 \\
\hline Downwelling velocity & 7,1565 & 2.195 & 35.800 & $<0.0001$ \\
\hline Camera $\times$ downwelling velocity & 7,1565 & 0.241 & 3.930 & $<0.001$ \\
\hline \multicolumn{5}{|c|}{ Horizontal absolute acceleration, log } \\
\hline Intercept & 1,1564 & 1225.744 & 16301.480 & $<0.0001$ \\
\hline Camera & 1,1564 & 0.035 & 0.470 & 0.495 \\
\hline Downwelling velocity & 7,1564 & 0.881 & 11.720 & $<0.0001$ \\
\hline Camera $\times$ downwelling velocity & 7,1564 & 0.310 & 4.130 & $<0.001$ \\
\hline \multicolumn{5}{|c|}{ Dominant period, vertical swimming velocity } \\
\hline Intercept & 1,838 & 14.179 & 303.043 & $<0.0001$ \\
\hline Camera & 1,838 & 0.858 & 18.339 & $<0.0001$ \\
\hline Downwelling velocity & 7,838 & 2.459 & 52.570 & $<0.0001$ \\
\hline Camera $\times$ downwelling velocity & 7,838 & 0.760 & 16.252 & $<0.0001$ \\
\hline \multicolumn{5}{|c|}{ Dominant period, horizontal swimming velocity } \\
\hline Intercept & 1,838 & 6.907 & 208.944 & $<0.0001$ \\
\hline Camera & 1,838 & 0.354 & 10.732 & 0.001 \\
\hline Downwelling velocity & 7,838 & 0.627 & 18.989 & $<0.0001$ \\
\hline Camera $\times$ downwelling velocity & 7,838 & 0.196 & 5.935 & $<0.0001$ \\
\hline \multicolumn{5}{|l|}{ Trajectory complexity index, log } \\
\hline Intercept & 1,1567 & 12.193 & 317.979 & $<0.0001$ \\
\hline Camera & 1,1567 & 0.359 & 9.377 & 0.002 \\
\hline Downwelling velocity & 7,1567 & 1.001 & 26.118 & $<0.0001$ \\
\hline Camera $\times$ downwelling velocity & 7,1567 & 0.067 & 1.751 & 0.093 \\
\hline
\end{tabular}

axis, respectively. Higher mean acceleration was also observed at downwelling velocities of $-0.67 \mathrm{~cm} \mathrm{~s}^{-1}$, especially for the horizontal accelerations measured by Camera A. The ANOVAs on absolute accelerations on both axis showed a significant effect of the interaction of water downwelling velocity $\times$ camera, as cameras measured different accelerations depending on the water speed (Table 1, Fig. 3).

\subsection{Copepod swimming behaviour}

Multimodal statistical tests for swimming vertical speeds showed unimodal distributions in most of the cases (Table S1, Fig. 4). The null hypothesis of one unique mode was rejected only twice out of 29 cases, at water velocities of -2.69 and $-5.38 \mathrm{~cm} \mathrm{~s}^{-1}$; the null hypothesis of bimodal distribution was accepted in these 2 cases (Table $\mathrm{S} 1$, Fig. 4). At water velocity of $-2.69 \mathrm{~cm}$ $\mathrm{s}^{-1}$, one of the modes was located at downward swimming speed of $-0.4 \mathrm{~cm} \mathrm{~s}^{-1}$ and the other at upward swimming velocities of $1.1 \mathrm{~cm} \mathrm{~s}^{-1}$ (Fig. 4F). At $-5.38 \mathrm{~cm} \mathrm{~s}^{-1}$, both modes were positive and more similar $(0.4$ and $1.53 \mathrm{~cm} \mathrm{~s}^{-1}$; Fig. 4H). Overall, like least square means, mode values increased with water downward velocities (Table S1).

Only 3 out of 29 videos showed significant changes in vertical swimming velocities among individuals with time (Fig. 5, Table S1). Consecutive rises and drops in vertical swimming speeds were observed at downwelling water velocities of $-0.67 \mathrm{~cm} \mathrm{~s}^{-1}$ (Fig. 5C). Abrupt changes in velocities occurred after few minutes, but also after only $12 \mathrm{~s}$ in one experiment at maximum downwards water flows of $-5.38 \mathrm{~cm} \mathrm{~s}^{-1}$ (Fig. 5H). For the rest of the videos, significant shifts in vertical swimming velocities were not observed.

Within each individual trajectory, the time periods identified by the Fourier analyses at which swimming velocities oscillated changed significantly between the levels of the interaction of camera $x$ water velocity (Table 1, Fig. 6). Mean periods ranged from $0.05-0.8 \mathrm{~s}$ and from $0.05-0.45 \mathrm{~s}$ 

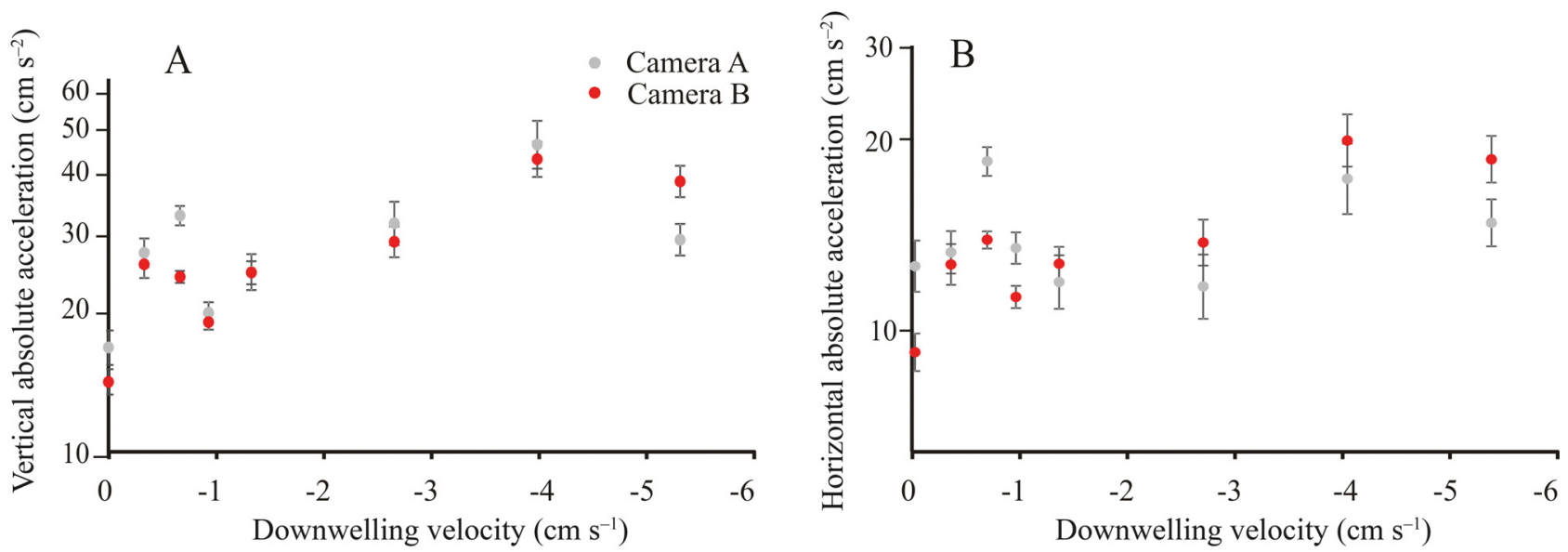

Fig. 3. Absolute (A) vertical and (B) horizontal accelerations of copepods at different downwelling velocities. Accelerations are represented on a logarithmic scale. Least square means $( \pm \mathrm{SE})$ from the ANOVA are shown. Only significant factors from this analysis are represented, in this case, the interaction of camera $\times$ water velocity
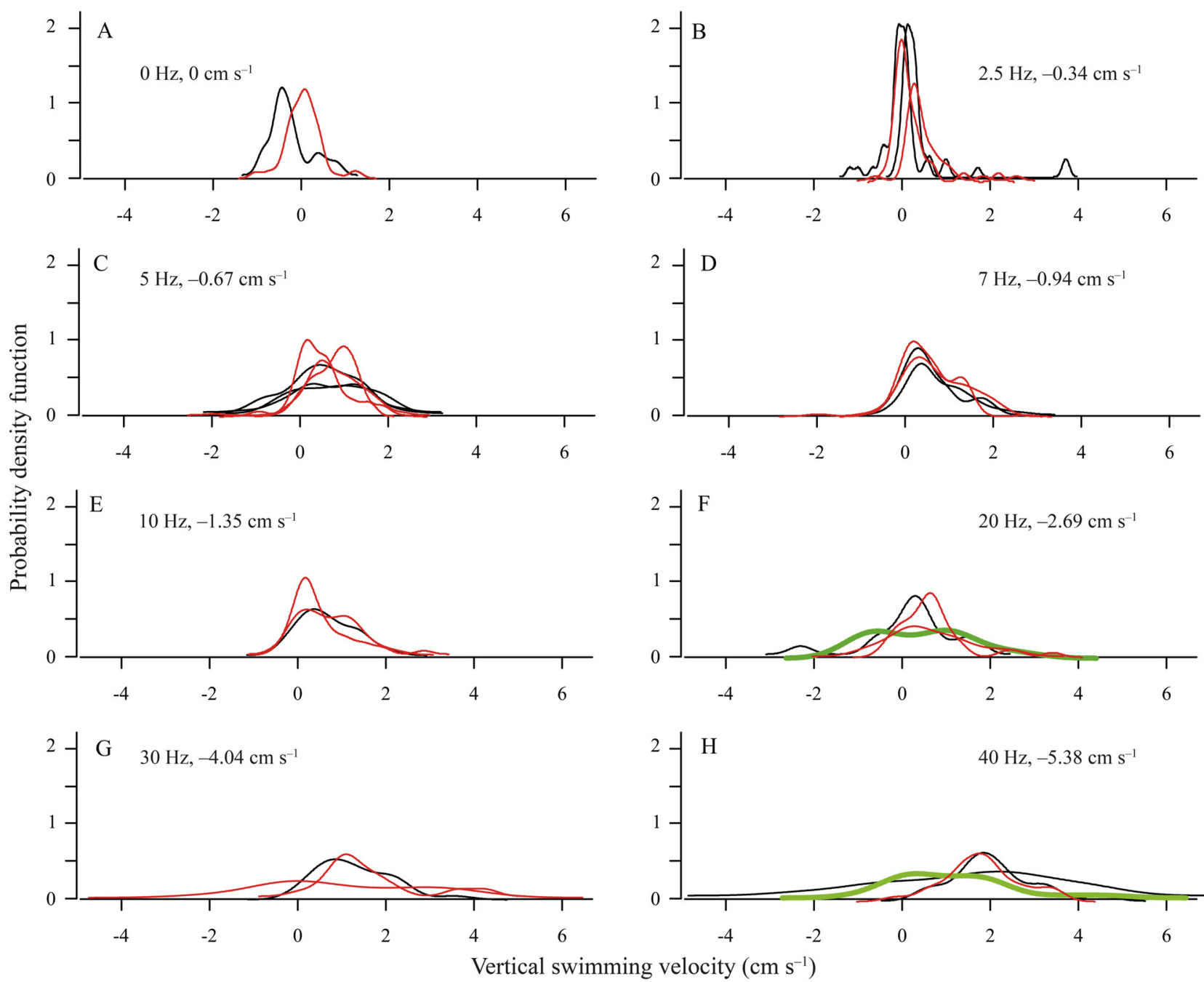

Fig. 4. (A-H) Probability density functions for all tests at each pump rate/vertical water velocity. Black and red lines: functions for Cameras A and B, respectively; green lines: probability functions for the only 2 tests with significant bimodal distributions:

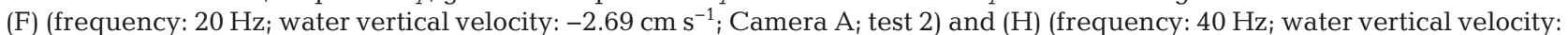
$-5.38 \mathrm{~cm} \mathrm{~s}^{-1}$; Camera $\mathrm{B}_{\text {; }}$ test 1 ). Unimodal and bimodal conditions were defined by excess mass statistical tests (see Table S1) 

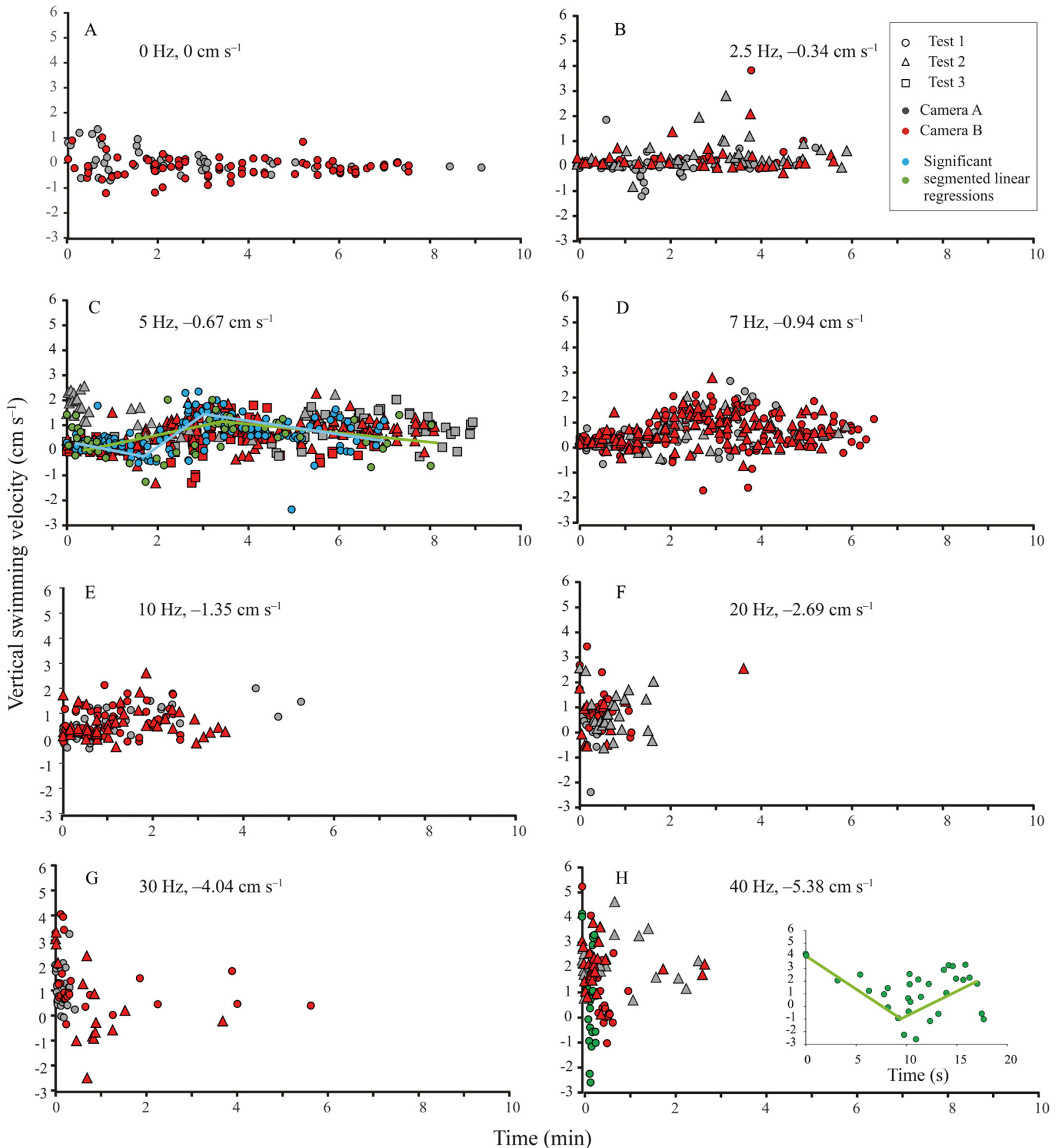

Fig. 5. (A-H) Individual mean swimming vertical velocities along video duration for each downwelling velocity. Each dot represents the mean vertical swimming speed of an individual copepod along its whole trajectory. Data from different tests and cameras are represented by symbols and colours according to the legend. Green and blue lines show segmented linear fits for Cameras A and B, respectively, in $(\mathrm{C})$ and $(\mathrm{H})$. Inset in $(\mathrm{H})$ shows a significant segmented linear fit during the first $20 \mathrm{~s}$ of recording

for the vertical and horizontal axis, respectively. Overall, dominant periods peaked at water velocities of $-0.34 \mathrm{~cm} \mathrm{~s}^{-1}$ and then became shorter with higher downwelling speeds. At $-0.34 \mathrm{~cm} \mathrm{~s}^{-1}$ the 2 cameras registered different dominant periods, with Camera B recording much longer time periods. Examples of individual periodograms showed that the shortest pos- sible period (0.04 s, 2 time intervals) was found to prevail at higher water speeds, especially at $-5.38 \mathrm{~cm}$ $\mathrm{s}^{-1}$. On the contrary, periodograms characterised by long periods of $1.5 \mathrm{~s}$ were found especially at $-0.34 \mathrm{~cm} \mathrm{~s}^{-1}$.

The ANOVA performed on the trajectory complexity index showed a significant effect of water velocity 

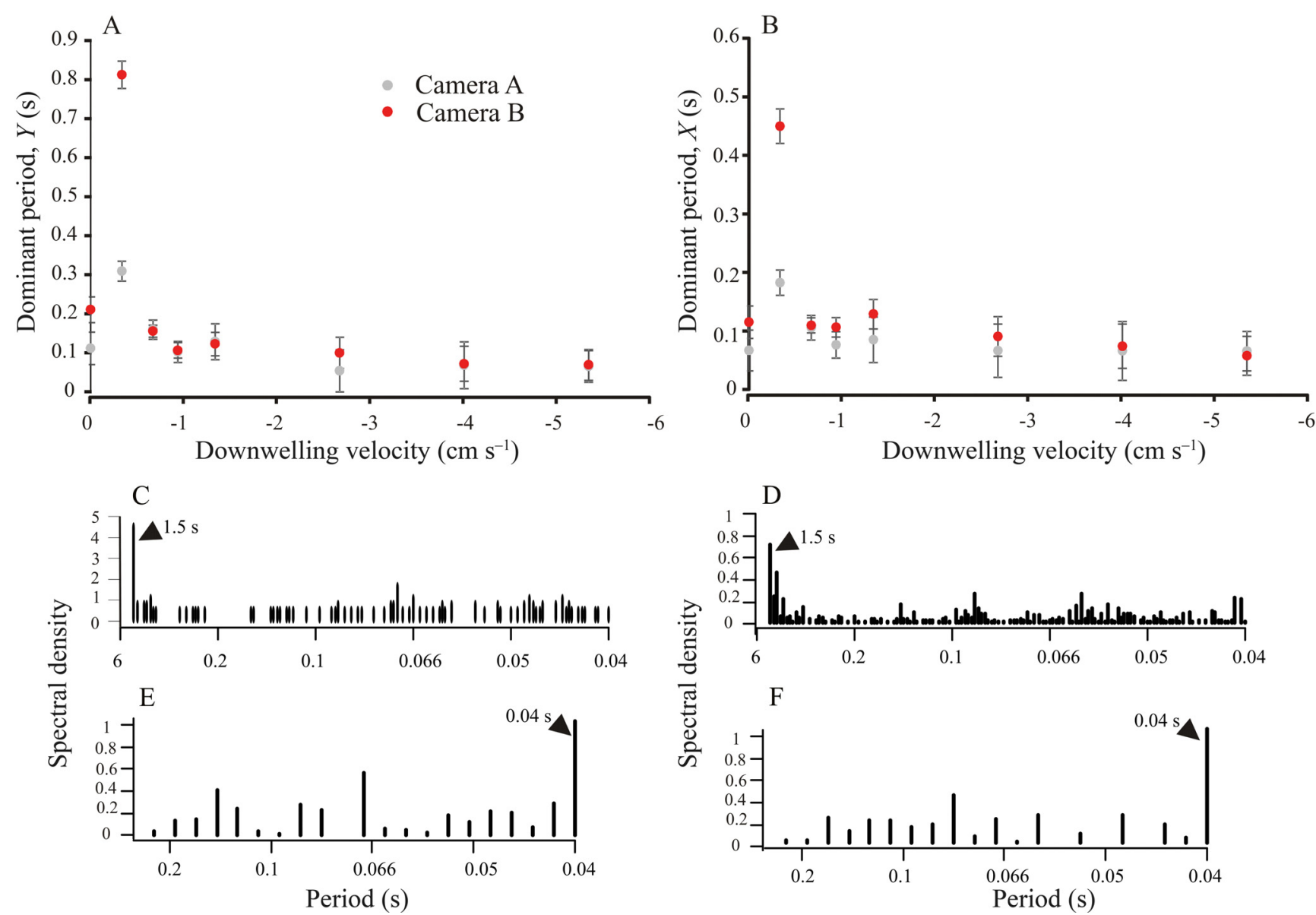

Fig. 6. Dominant periods from Fourier spectral analyses on (A) vertical and (B) horizontal velocities at different water vertical velocities. Least square means $( \pm \mathrm{SE})$ from the ANOVA are shown. Only significant factors from this analysis are represented, in this case, camera $\times$ water velocity. Examples of Fourier spectral analyses on (C) vertical and (D) horizontal velocities charac-

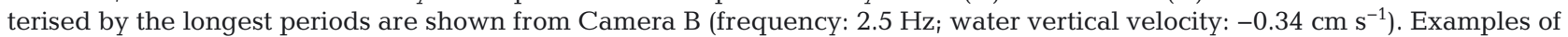
Fourier spectral analyses on $(\mathrm{E})$ vertical and $(\mathrm{F})$ horizontal velocities characterised by the shortest periods are shown from Camera A (frequency: $40 \mathrm{~Hz}$; water vertical velocity: $-5.38 \mathrm{~cm} \mathrm{~s}^{-1}$ ). Note that the scale on the $x$-axis of $(\mathrm{C}-\mathrm{F})$ has been derived from a linear scale of frequencies

and camera (Table 1, Fig. 7). Mean index values ranged from 1.2-1.9. Again, significant differences between cameras were minor compared to those found between water velocity treatments, with Camera B showing slightly more complex trajectories (Fig. 7). Trajectory complexity means peaked at $-0.34 \mathrm{~cm} \mathrm{~s}^{-1}$ and then dropped markedly as downwelling velocities increased. Particular examples showed very complex movement patterns, with a very convoluted trajectory showing the highest index (139) at water velocity $0 \mathrm{~cm} \mathrm{~s}^{-1}$ (Fig. 7C). On the contrary, very simple sinking trajectories were recorded at higher water downwelling speeds, with the lowest index value (1.00002) measured at a downwelling water velocity of $-2.69 \mathrm{~cm} \mathrm{~s}^{-1}$ (Fig. 7D).

Dominant periods and trajectory complexity indexes decreased with vertical swimming velocities following very significant power law fits explaining large amounts of variability (Fig. 8). These fits did not apply to dominant periods and complexity indexes measured at null downwelling velocities when swimming speeds were close to 0 .

\section{DISCUSSION}

Although the 2 cameras used did not measure the exact same swimming velocities of copepods, we observed clear behavioural shifts as a function of downwelling currents. Overall, Calanus spp. copepods were able to swim upwards at maximum velocities of about $2 \mathrm{~cm} \mathrm{~s}^{-1}$, thus matching vertical currents usually observed in the open ocean (on the order of several $\mathrm{mm} \mathrm{s}^{-1}$ ) and in turn keeping vertical position. At 

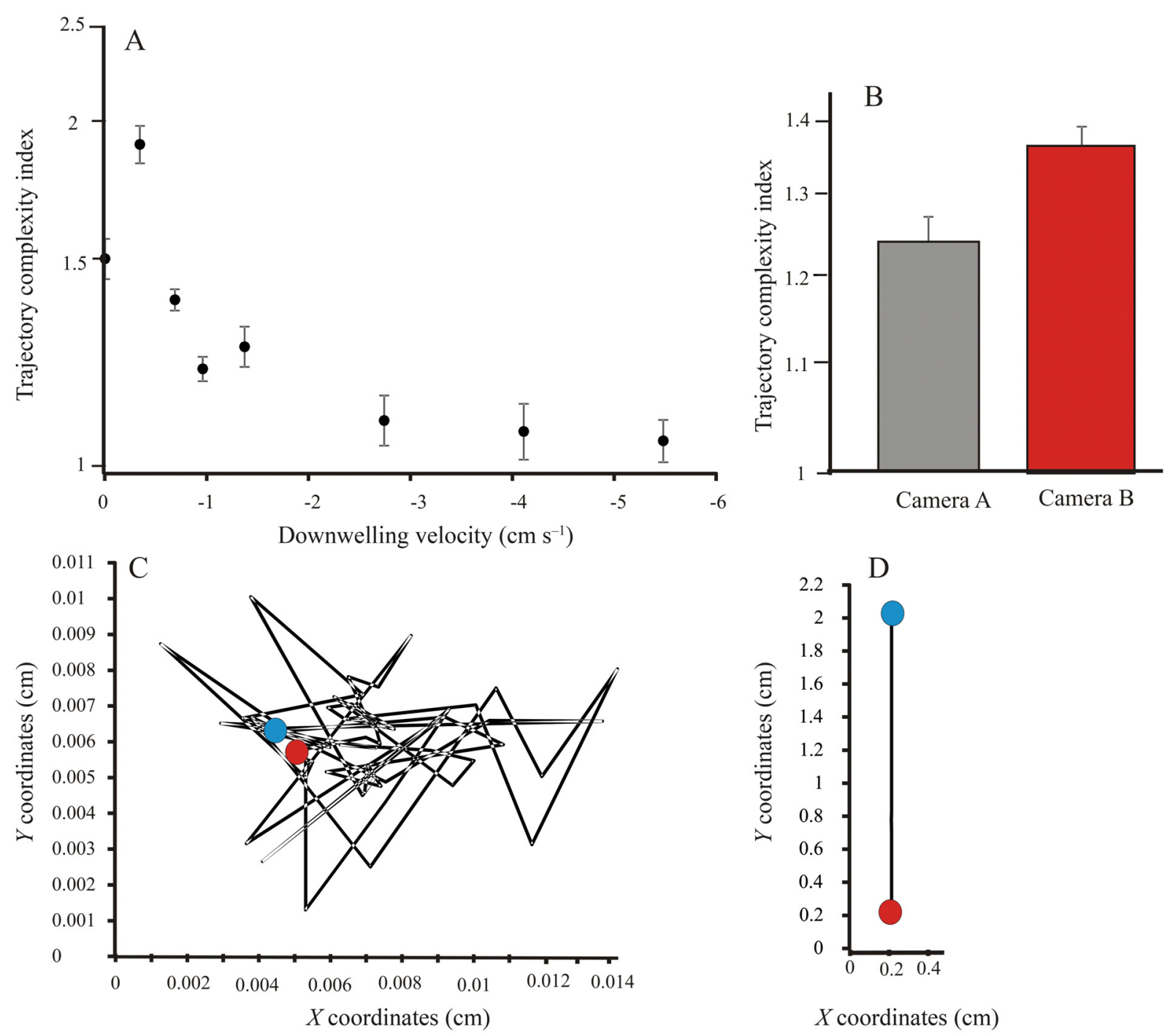

Fig. 7. Trajectory complexity index at different downwelling velocities. Least square means $( \pm$ SE) from the ANOVA are shown. Index values are represented on a logarithmic scale. Only significant factors from this analysis are represented, in this case, (A) water velocity and (B) camera. The most complex and the simplest recorded trajectories are shown, with 2 examples from (C) Camera B (frequency: $0 \mathrm{~Hz}$; water vertical velocity: $0 \mathrm{~cm} \mathrm{~s}^{-1}$; complexity index: 139.07) and (D) Camera A (frequency: $20 \mathrm{~Hz}$; water vertical velocity: $-2.69 \mathrm{~cm} \mathrm{~s}^{-1}$; complexity index: 1.00002). Blue and red circles mark the beginning and end of the trajectories, respectively

higher downwelling currents, copepods substantially reduced their sinking rates, a feature that can be important in order to maintain the cohesion of largescale surface swarms. However, their behaviour was clearly affected by high downwelling flows: time scales of swimming speed fluctuations were reduced, accelerations increased and swimming trajectories became shorter (Figs. 3, $6 \&$ 7). These behavioural features are consistent with a trade-off between the swimming speed required to maintain a preferred vertical position and balancing between predator avoidance and food encounter rates (Visser \& Kiør- boe 2006). As mating and feeding depend on swimming in cruising mode (Tiselius \& Jonsson 1990), changes in downwelling water velocities can affect copepod overall fitness. On the other hand, our results indicate that a certain degree of downwelling flow may be required to trigger cruising. More complex, convoluted movement patterns with less drastic accelerations on longer time scales were observed at downwelling velocities of $-0.34 \mathrm{~cm} \mathrm{~s}^{-1}$, not at $0 \mathrm{~cm}$ $\mathrm{s}^{-1}$. Thus, copepod behaviour appears to be finely tuned in line with commonly observed vertical flows across the water column. 


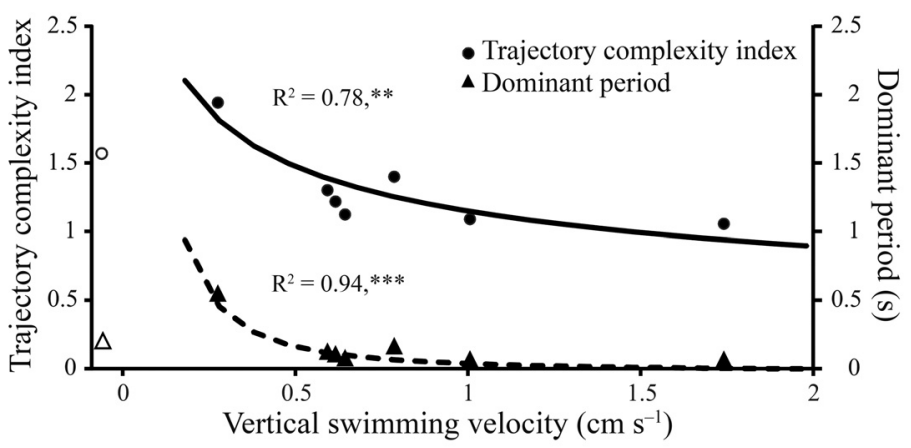

Fig. 8. Power law fits between trajectory complexity index, dominant period and vertical swimming velocity. Empty symbols: measurements that were not considered for the regressions. Variance explained and statistical significance are reported $\left({ }^{* *} \mathrm{p}<0.01 ;{ }^{* * *} \mathrm{p}<0.001\right)$

\subsection{Swimming against vertical currents}

Swimming against vertical flow to maintain depth provides several advantages to planktonic populations. For coastal zooplankton and marine invertebrate larvae, it allows nearshore retention by staying in those water layers moving onshore under contrasting scenarios of upwelling and downwelling (Genin et al. 2005, Shanks \& Brink 2005, Shanks \& Shearman 2009). For subarctic and Arctic pelagic holoplankton, e.g. copepods of the genus Calanus, swimming upward in the water column is crucial to remain within the productive surface waters during the short spring season at those latitudes. By grazing on the spring surface primary production, the next generation of calanoid copepods is able to grow from copepodite I-V while accumulating lipid reserves for overwintering at great depths (Halvorsen et al. 2003, Pond \& Tarling 2011, Weidberg \& Basedow 2019).

Vertical currents in the ocean usually attain speeds of several $\mathrm{mm} \mathrm{s}^{-1}$ or less. Oceanic gyres can generate vertical flows in the order of $0.01-0.1 \mathrm{~mm}$ $\mathrm{s}^{-1}$ and often develop off northern Norway (Pedersen et al. 2005, Bashmachnikov et al. 2017). Under this environmental forcing, our results suggest that copepods can keep their vertical position while maintaining cruising behaviours with reduced accelerations and complex trajectories on longer time scales. However, under some conditions, stronger vertical currents between a few $\mathrm{cm} \mathrm{s}^{-1}$ and $50 \mathrm{~cm} \mathrm{~s}^{-1}$ can develop in the pelagic realm, including at downwelling plume fronts (Kilcher \& Nash 2010) and at breaking internal waves (Aghsaee et al. 2010, Richards et al. 2013). These physical structures also occur at one of the copepods' main spring habitats, within the surface waters of the Norwegian
Coastal Current (NCC) (Basedow et al. 2019, Weidberg et al. unpubl. data). Plume fronts characterised by strong downwelling currents can be formed between the NCC and saltier offshore waters, and the pycnocline created by the presence of the surface buoyant layer of the NCC can trigger the propagation and breaking of internal waves (Sætre 1999, Dokken et al. 2001). Although these are all transient oceanographic processes at a single location, zooplankton can be retained inside internal wave fronts and within buoyant water masses like the NCC (Hetland et al. 2002, Helfrich \& Pineda 2003, Weidberg et al. 2014). Downwelling currents would then become persistent for the copepods. Even if downwelling currents only occur briefly and occasionally, copepods would not be able to maintain their vertical position when facing strong downwelling velocities. In those cases, copepods can at least reduce their sinking rates. For instance, at maximum downward currents of $5.38 \mathrm{~cm} \mathrm{~s}^{-1}$, animals were observed to swim upwards at a mean speed of almost $2 \mathrm{~cm} \mathrm{~s}^{-1}$, thus reducing their downward displacement to $3.38 \mathrm{~cm} \mathrm{~s}^{-1}$ (Fig. 2). Thus, after the dissipation of such downwelling currents, copepods would be able to reach the upper layers and resume their usual swimming activities in relatively short time.

Field observations are largely consistent with our experimental results. The same threshold of $\sim 2 \mathrm{~cm}$ $\mathrm{s}^{-1}$ was observed for the copepod Dioithona oculata, which cannot keep its position when facing faster currents (Buskey et al. 1995, Ambler 2002). Other studies point to even more vigorous behaviours evolved to retain vertical positions. In the Gulf of Aquaba, persistent upwelling and downwelling forcing in conjunction with nearshore topography cause strong vertical currents of several $\mathrm{cm} \mathrm{s}^{-1}$ (Genin et al. 2005). There, water vertical currents and vertical swimming speeds of the zooplankton community, mostly copepods, were simultaneously measured. It was found that within a range of vertical currents in between 6 and $-6 \mathrm{~cm} \mathrm{~s}^{-1}$, compensatory swimming speeds in the opposite direction were between 100 and $82 \%$ of the vertical currents, thus allowing an almost complete depth retention (Genin et al. 2005). Over Georges Bank, vertical velocities of calanoid copepods up to $3 \mathrm{~cm} \mathrm{~s}^{-1}$ easily overcome vertical currents of several $\mathrm{mm} \mathrm{s}^{-1}$ (Gallager et al. 2004). In the laboratory and using essentially the same experimental setting as in our study, barnacle cyprid larvae were observed to attain mean upward velocities of $2 \mathrm{~cm} \mathrm{~s}^{-1}$ when facing downward flows of $4.7 \mathrm{~cm} \mathrm{~s}^{-1}$ (DiBacco et al. 2011). 
Cyprids may be stronger swimmers than most components of the mesozooplankton, as they are a nonfeeding stage that accumulates energy reserves from 6 previous naupliar stages, their bullet-shape morphology is highly hydrodynamic and they are able to cover 90 times their body length in $1 \mathrm{~s}$ (Anderson 1994). How these different zooplankton species perceive the environmental cues that trigger these responses has been strongly debated. Copepods can potentially sense changes in pressure equivalent to distances of a few $\mathrm{cm}$ across the vertical axis (Knight-Jones \& Morgan 1966, Genin et al. 2005). In addition, cuticular mechanoreceptors allow for the perception of flow direction and strength and in turn enable positive rheotaxis (Casas \& Dangles 2010, Yen et al. 2015).

\subsection{Swimming behaviour}

Copepods can exhibit a wide range of swimming behaviours, but cruising usually prevails in calanoid copepods as it increases encounter rates with food items and facilitates mate-finding under normal environmental conditions (Tiselius \& Jonsson 1990, Tsuda \& Miller 1998, Chen \& Hwang 2018). Our results suggest a significant decrease in cruising behaviours as downwelling velocity increased. In particular, downwelling velocities greater than ca. $2 \mathrm{~cm}$ $\mathrm{s}^{-1}$ were consistent with a reduction of relatively slow, constant motions of copepods along a complex trajectory. Similarly, stronger and more turbulent flows induced faster swimming velocities in Eurytemora affinis, but reduced the gender-specific highly complex trajectories which increase matefinding rates (Michalec et al. 2015).

The above observations could reflect a trade-off between the correlation time scale and swimming speed resulting in the optimisation of the correlation length scale (Visser \& Kiørboe 2006). If we assume that the dominant period obtained from our periodogram analyses on vertical velocity time series is a good proxy of the correlation time scale, then it decreased as swimming velocities increased following a power law function (Fig. 8) Therefore, our results suggest that as the animals are forced to increase their swimming speeds to retain their vertical position, the dominant periods at which their swimming velocities fluctuate become shorter to keep correlation length scales within an optimal range. Trajectory complexity also decreased sharply with swimming speed (Fig. 8), probably due to motion limitations imposed by the downwelling flows. In agreement with our results, energetic, turbulent conditions were observed to reduce path convolutedness in E. affinis (Michalec et al. 2015). On the other hand, when downwelling water velocities became zero, the period/velocity trade-off did not apply as swimming velocities were almost zero, dominant periods decreased and simpler trajectories prevailed (Figs. 2, $6 \& 8)$. In this particular scenario, staying at the preferred depth probably becomes more important than the optimisation of predator/food encounter rates. Zero vertical speeds were also observed in cyprids at zero water downwelling velocities (DiBacco et al. 2011). Nevertheless, it is highly unlikely that zooplankton will experience the total absence of any vertical flow in the open ocean due to the occurrence of many different hydrographic processes involved in the vertical displacement of water masses.

In contrast to cyprids (DiBacco et al. 2011), unimodality prevailed over bimodal distributions of vertical swimming speeds of copepods in our study. In general, mode values increased with downwelling speed, indicating that the whole population responded in the same way to the vertical flows (Table S1). It is possible that the intrinsic bias towards individuals that swam upwards, thus remaining in the field of view of the camera, was greater in copepods than in cyprids. Thus, those copepods that were rapidly washed away may not have been recorded enough times to constitute a clear mode at negative vertical velocities. On the other hand, we found evidence of synchronised swimming behaviours in 3 out of 29 available videos, which showed consecutive rises and drops in individual swimming velocities (Table S1, Fig. 5). The observed alternating upward swimming and sinking behaviours have been shown to save energy with respect to the costs of keeping a constant velocity in time (Haury \& Weihs 1976). Modulation in swimming speeds in response to predator chemical cues was also observed in swarms of Daphnia pulex, which showed more constant swimming speeds when exposed to fish kairomones (Jensen et al. 1998). In turn, flow perturbations produced by one copepod can be perceived and imitated by another one, allowing the formation of swarms while keeping a minimum distance between individuals (Jiang et al. 2002). However, this interpretation has to be taken with caution, as alternating swimming velocities were not observed in the majority of our experiments. In addition, temporal variability in the flow within the chamber could occur and explain the oscillating swimming behaviours, as there was variability in downwelling velocities at fixed pump rates (Fig. 1). 


\section{CONCLUSIONS}

The behaviours recorded in our experimental setting show that Calanus finmarchicus was able to swim against rather strong downward flows up to $2 \mathrm{~cm} \mathrm{~s}^{-1}$, thus allowing depth retention in normal hydrodynamic conditions across the water column. Changes in trajectory complexity and significant movement periodicity are largely consistent with a trade-off between active vertical positioning on the one hand and feeding and predator avoidance optimisation on the other hand.

Acknowledgements. This work was supported and funded by the Sea Patches project (grant number 268391/E40) of the Norwegian Research Council and by the collaborative agreement F5284-180227 between Fisheries and Oceans Canada and the UiT The Arctic University of Norway. During data processing and manuscript elaboration, N.W. was funded by NASA grant 80NSSC20K0074. We thank Per Gjerp, John-Terje Eilertsen and Hans Dybvik for their technical assistance in the installation of the observation chamber and water circulation system. The authors also thank Kunuk Lennert for helping in animal collection on board the R/V 'Hyas'. Paul Dubourg and Guillaume Schuler also provided valuable assistance during field and laboratory work.

\section{LITERATURE CITED}

Aghsaee P, Boegman L, Lamb KG (2010) Breaking of shoaling internal solitary waves. J Fluid Mech 659:289-317

Ambler JW (2002) Zooplankton swarms: characteristics, proximal cues and proposed advantages. Hydrobiologia 480:155-164

*Ameijeiras-Alonso J, Crujeiras RM, Rodríguez-Casal A (2019) Mode testing, critical bandwidth and excess mass. Test 28:900-919

Anderson DT (1994) Larval development and metamorphosis. In: Anderson DT (ed) Barnacles: structure, function, development and evolution. St Edmundsbury Press, London, p 197-239

Archambault P, Roff JC, Bourget E, Bang B, Ingram GR (1998) Nearshore abundance of zooplankton in relation to shoreline configuration and mechanisms involved. J Plankton Res 20:671-690

Bachiller E, Skaret GL, Nøttestad A, Slotte A (2016) Feeding ecology of northeast Atlantic mackerel, Norwegian spring spawning herring and blue whiting in the Norwegian Sea. PLOS ONE 11:e0149238

Barham EG (1963) Siphonophores and the deep scattering layer. Science 140:826-828

Basedow SL, McKee D, Lefering I, Gislason A and others (2019) Remote sensing of zooplankton swarms. Sci Rep 9: 686

Bashmachnikov IL, Sokolovskiy MA, Belonenko TV, Volkov DL, Isachsen PE, Carton X (2017) On the vertical structure and stability of the Lofoten vortex in the Norwegian Sea. Deep Sea Res I 128:1-27

Bianco G, Botte V, Dubroca L, Ribera d'Alcalà M, Mazzocchi MG (2013) Unexpected regularity in swimming behavior of Clausocalanus furcatus revealed by a telecentric 3D computer vision system. PLOS ONE 8:e67640
Bonnet D, Lindeque PK, Harris RP (2010) Sagitta setosa predation on Calanus helgolandicus in the English Channel. J Plankton Res 32:725-737

*Buskey EJ (1984) Swimming pattern as an indicator of the roles of copepod sensory system in the recognition of food. Mar Biol 79:165-175

Buskey EJ, Peterson JO, Ambler JW (1995) The role of photoreception in the swarming behavior of the copepod Dioithona oculata. Mar Freshwat Behav Physiol 26:273-285

* Carstensen J, Weydmann A, Olszewska A, Kwaśnieski S (2012) Effects of environmental conditions on the biomass of Calanus spp. in the Nordic seas. J Plankton Res 34:951-966

Casas J, Dangles O (2010) Physical ecology of fluid flow sensing in arthropods. Annu Rev Entomol 55:505-520

Chan KS, Ripley B (2018) TSA: time series analysis. R package version 1.2. https://cran.r-project.org/package=TSA

Chen MR, Hwang JS (2018) The swimming behavior of the calanoid copepod Calanus sinicus under different food concentrations. Zool Stud 57:e13

Choquet M, Hatlebakk M, Dhanasiri AKS, Kosobokova K and others (2017) Genetics redraws pelagic biogeography of Calanus. Biol Lett 13:20170588

Cottier FR, Tarling GA, Wold A, Falk-Petersen S (2006) Unsynchronised and synchronised vertical migration of zooplankton in a high Arctic fjord. Limnol Oceanogr 51: 2586-2599

* Croxall JP, Hill HJ, Lidstone-Scott R, O'Connell MJ, Prince PA (1988) Food and feeding ecology of Wilson's storm petrel Oceanites oceanicus at South Georgia. J Zool 216:83-102

* Davies RB (2002) Hypothesis testing when a nuisance parameter is present only under the alternative: linear model case. Biometrika 89:484-489

*DiBacco C, Fuchs HL, Pineda J, Helfrich K (2011) Swimming behavior and velocities of barnacle cyprids in a downwelling flume. Mar Ecol Prog Ser 433:131-148

Dokken ST, Olsen R, Wahl T, Tantillo MV (2001) Identification and characterization of internal waves in SAR images along the coast of Norway. Geophys Res Lett 28: 2803-2806

Enright JT (1977) Diurnal vertical migration: adaptive significance and timing. Part 1 . Selective advantage: a metabolic model. Limnol Oceanogr 222:856-872

Field A (2013) Discovering statistics using IMB SPSS Statistics, $4^{\text {th }}$ edn. SAGE Publications, London

Fields DM, Shema SD, Browman HI, Browne TQ, Skiftesvik AB (2012) Light primes the escape response of the calanoid copepod, Calanus finmarchicus. PLOS ONE 7 : e39594

Fiksen Ø, Carlotti F (1998) A model of optimal life history and diel vertical migration in Calanus finmarchicus. Sarsia 83:129-147

KFrescura FAM, Engelbrecht CA, Frank BS (2008) Significance of periodogram peaks and a pulsation mode analysis of the Beta Cephei star V403 Car. Mon Not R Astron Soc 388:1693-1707

*Gallager SM, Yamazaki H, Davis CS (2004) Contribution of fine-scale vertical structure and swimming behavior to formation of plankton layers on Georges Bank. Mar Ecol Prog Ser 267:27-43

*Genin A, Jaffe SJ, Reef R, Richter C, Franks PJS (2005) Swimming against the flow: a mechanism of zooplankton aggregation. Science 308:860-862

Halvorsen E, Tande KS, Edvardsen A, Slagstad D, Pedersen OP (2003) Habitat selection of overwintering Calanus finmarchicus in the NE Norwegian Sea and shelf waters off northern Norway in 2000-02. Fish Oceanogr 12:339-351 
Hardy AC, Bainbridge R (1954) Experimental observations on the vertical migrations of plankton animals. J Mar Biol Assoc UK 33:409-448

*Haury L, Weihs D (1976) Energetically efficient swimming behavior of negatively buoyant zooplankton. Limnol Oceanogr 21:797-803

Haury LR, Kenyon DE, Brooks JR (1980) Experimental evaluation of the avoidance reaction of Calanus finmarchicus. J Plankton Res 2:187-202

Helfrich KR, Pineda J (2003) Accumulation of particles in propagating fronts. Limnol Oceanogr 48:1509-1520

Hetland RD, McGillicuddy DJ, Signell RP (2002) Crossfrontal entrainment of plankton into a buoyant plume: the frog tongue mechanism. J Mar Res 60:763-777

Hirche HJ (1996) Diapause in the marine copepod, Calanus finmarchicus - a review. Ophelia 44:129-143

* Jensen KH, Jakobsen PJ, Kleiven OT (1998) Fish kairomones regulation of internal swarm structure in Daphnia pulex (Cladocera: Crustacea). Hydrobiologia 368:123-127

Jiang H, Osborn TR, Meneveau C (2002) Hydrodynamic interaction between two copepods: a numerical study. J Plankton Res 24:235-253

Kilcher LF, Nash JD (2010) Structure and dynamics of the Columbia River tidal plume front. J Geophys Res 115: C05S90

Kiørboe T, Andersen A, Langlois VJ, Jakobsen HH (2010) Unsteady motion: escape jumps in planktonic copepods, their kinematics and energetics. J R Soc Interface 7: 1591-1602

Knight-Jones EW, Morgan E (1966) Responses of marine animals to changes in hydrostatic pressure. Oceanogr Mar Biol Annu Rev 4:267-299

* Le Quéré C, Buitenhuis ET, Moriarty R, Alvain S and others (2016) Role of zooplankton dynamics for Southern Ocean phytoplankton biomass and global biogeochemical cycles. Biogeosciences 13:4111-4133

Lenz PH, Hower AE, Hartline DK (2004) Force production during pereiopod power strokes in Calanus finmarchicus. J Mar Syst 49:133-144

Mann R (1988) Distribution of bivalve larvae at a frontal system in the James River, Virginia. Mar Ecol Prog Ser 50: 29-44

Michalec FG, Souissi S, Holzner M (2015) Turbulence triggers vigorous swimming but hinders motion strategy in planktonic copepods. J R Soc Interface 12:20150158

Moriarty R, O'Brien TD (2013) Distribution of mesozooplankton biomass in the global ocean. Earth Syst Sci Data 5:45-55

Muggeo VMR (2019) segmented: regression models with break points/change-points estimation. $\mathrm{R}$ package version 1.0. https://cran.r-project.org/package=segmented

Müller DW, Sawitzki G (1991) Excess mass estimates and tests for multimodality. J Am Stat Assoc 86:738-746

Pedersen OP, Zhou M, Tande KS, Edvardsen A (2005) Eddy formation on the coast of North Norway - evidenced by synoptic sampling. ICES J Mar Sci 62:615-628

Pineda J (1999) Circulation and larval distribution in internal tidal bore warm fronts. Limnol Oceanogr 44:1400-1414

Pond DW, Tarling GA (2011) Phase transitions of wax esters adjust buoyancy in diapausing Calanoides acutus. Limnol Oceanogr 56:1310-1318

Queiroga H, Blanton JO (2004) Interactions between behaviour and physical forcing in the control of horizontal transport of decapod crustacean larvae: an overview. Adv Mar Biol 47:107-214

Editorial responsibility: Marsh Youngbluth,

Fort Pierce, Florida, USA

Reviewed by: 3 anonymous referees
R Core Team (2020) R: a language and environment for statistical computing. R Foundation for Statistical Computing, Vienna. www.r-project.org

* Richards CD, Bourgault D, Galbraith PS, Hay A, Kelley DE (2013) Measurements of shoaling internal waves and turbulence in an estuary. J Geophys Res Oceans 118: $273-286$

* Sætre R (1999) Features of the central Norwegian shelf circulation. Cont Shelf Res 19:1809-1831

Sars GO (1903) An account of the Crustacea of Norway, Vol 4: Copepoda, Calanoida. Bergen Museum, Bergen

Scargle JD (1982) Studies in astronomical time series analysis. II. Statistical aspects of spectral analysis of unevenly spaced data. Astrophys J 263:835-853

Shanks AL, Brink L (2005) Upwelling, downwelling, and cross-shelf transport of bivalve larvae: test of a hypothesis. Mar Ecol Prog Ser 302:1-12

* Shanks AL, Shearman RK (2009) Paradigm lost? Cross-shelf distributions of intertidal invertebrate larvae are unaffected by upwelling or downwelling. Mar Ecol Prog Ser 385:189-204

K Shanks AL, Largier JL, Brink L, Brubaker J, Hoof R (2000) Demonstration of the onshore transport of larval invertebrates by the shoreward movement of an upwelling front. Limnol Oceanogr 45:230-236

Silverman BW (1981) Using kernel density estimates to investigate multimodality. J R Stat Soc B 43:97-99

Silverman BW (1986) Density estimation for statistics and data analysis. Chapman \& Hall, London

Tarling GA, Jarvis T, Emsley SM, Matthews JBL (2002) Midnight sinking behaviour in Calanus finmarchicus: A response to satiation or krill predation? Mar Ecol Prog Ser 240:183-194

*Taylor GI (1921) Diffusion by continuous movements. Proc Lond Math Soc 20:196-212

*Tiselius P, Jonsson PR (1990) Foraging behaviour of six calanoid copepods: observations and hydrodynamic analysis. Mar Ecol Prog Ser 66:23-33

*Tsuda A, Miller CB (1998) Mate-finding behaviour in Calanus marshallae Frost. Philos Trans R Soc B 353: 713-720

*van Duren LA, Videler JL (1996) The trade-off between feeding, mate seeking and predator avoidance in copepods: behavioural responses to chemical cues. J Plankton Res 18:805-818

*Visser AW, Jónasdóttir SH (1999) Lipids, buoyancy and the seasonal vertical migration of Calanus finmarchicus. Fish Oceanogr 8:100-106

Visser AW, Kiørboe T (2006) Plankton motility patterns and encounter rates. Oecologia 148:538-546

Weidberg N, Basedow SL (2019) Long-term variability in overwintering copepod populations in the Lofoten Basin: the role of the North Atlantic oscillation and trophic effects. Limnol Oceanogr 64:2044-2058

* Weidberg N, Lobón C, López E, García Flórez L, Fernández Rueda MP, Largier JL, Acuña JL (2014) Effect of nearshore slicks on meroplankton distributions: role of larval behaviour. Mar Ecol Prog Ser 506:15-30

Yen J, Murphy DW, Fan L, Webster DR (2015) Sensorymotor systems of copepods involved in their escape from suction feeding. Integr Comp Biol 55:121-133

Karubin M, Lindeman Y, Brunner O, Fields DM, Browman HI, Genin A (2016) The effect of hydrostatic pressure on grazing in three calanoid copepods. J Plankton Res 38: $131-138$

Submitted: August 24, 2020

Accepted: February 19, 2021

Proofs received from author(s): April 11, 2021 